\title{
Antitumoral Potential of Tunisian Snake Venoms Secreted Phospholipases $\mathbf{A}_{2}$
}

\author{
Raoudha Zouari-Kessentini,, ${ }^{1,2}$ Najet Srairi-Abid,, ${ }^{1,2}$ Amine Bazaa, ${ }^{1,2}$ Mohamed El Ayeb, \\ Jose Luis, ${ }^{3,4}$ and Naziha Marrakchi ${ }^{1,2,5}$ \\ ${ }^{1}$ Laboratoire des Venins et Biomolecules Therapeutiques, Institut Pasteur de Tunis, 13, Place Pasteur, 1002 Tunis, Tunisia \\ ${ }^{2}$ Université de Tunis el Manar, 1068 Tunis, Tunisia \\ ${ }^{3}$ Centre de Recherche en Oncologie Biologique et Oncopharmacologie (CRO2), INSERM UMR 911, Marseille, France \\ ${ }^{4}$ Université d'Aix-Marseille, Marseille, France \\ ${ }^{5}$ Faculté de Médecine de Tunis, 1007 Tunis, Tunisia
}

Correspondence should be addressed to Raoudha Zouari-Kessentini; zouari_raoudha@yahoo.fr

Received 19 July 2012; Accepted 4 September 2012

Academic Editor: Luis A. Ponce Soto

Copyright (C) 2013 Raoudha Zouari-Kessentini et al. This is an open access article distributed under the Creative Commons Attribution License, which permits unrestricted use, distribution, and reproduction in any medium, provided the original work is properly cited.

\begin{abstract}
Phospholipases type $\mathrm{A}_{2}\left(\mathrm{PLA}_{2} \mathrm{~s}\right)$ are the most abundant proteins found in Viperidae snake venom. They are quite fascinating from both a biological and structural point of view. Despite similarity in their structures and common catalytic properties, they exhibit a wide spectrum of pharmacological activities. Besides being hydrolases, secreted phospholipases $\mathrm{A}_{2}\left(\mathrm{sPLA}_{2}\right)$ are an important group of toxins, whose action at the molecular level is still a matter of debate. These proteins can display toxic effects by different mechanisms. In addition to neurotoxicity, myotoxicity, hemolytic activity, antibacterial, anticoagulant, and antiplatelet effects, some venom $\mathrm{PLA}_{2}$ s show antitumor and antiangiogenic activities by mechanisms independent of their enzymatic activity. This paper aims to discuss original finding against anti-tumor and anti-angiogenic activities of sPLA ${ }_{2}$ isolated from Tunisian vipers: Cerastes cerastes and Macrovipera lebetina, representing new tools to target specific integrins, mainly, $\alpha 5 \beta 1$ and $\alpha \mathrm{v}$ integrins.
\end{abstract}

\section{Introduction}

Snake venom is a natural biological resource, containing several neurotoxic, cardiotoxic, cytotoxic, and many other different active compounds $[1,2]$. Due to this broad range of biological functions, these biomolecules have been the subject of hundreds of scientific articles in different research fields, including biochemistry, biophysics, pharmacology, toxicology, and medicine [2-5]. Viperidae snake venoms contain class II PLA ${ }_{2} \mathrm{~s}$, which share structural features with secreted $\mathrm{PLA}_{2}\left(\mathrm{sPLA}_{2}\right)$ of the class II-A present in inflammatory exudates in mammals. A number of venom $\mathrm{PLA}_{2} \mathrm{~s}$ have been shown to induce a variety of pharmacological effects although comprehensive studies of the actions of venom $\mathrm{PLA}_{2} \mathrm{~s}$ in the various events of toxicity are scarce $[6,7]$.

\section{Viperidae Snake Venom Phospholipase $A_{2}$ Enzymes: Secreted Phospholipases $\mathrm{A}_{2}$}

Secreted PLA 2 constitute a large superfamily of enzymes that are widely distributed in living organisms. The $\mathrm{SPA}_{2}$ from Viperidae snake venoms fall under group II. They are generally $\mathrm{Ca}^{2+}$-dependant enzymes that catalyze the hydrolysis of the sn-2 fatty acid bond of phospholipids to release free fatty acids and lysophospholipids [7]. These enzymes are small proteins $(\sim 13-14 \mathrm{kDa})$, containing $120-125$ aminoacid residues, 7 disulfide bridges, and have a partially conserved 
structure that define the $\mathrm{PLA}_{2}$ fold [8]. Group II snake venom $\mathrm{PLA}_{2}$ enzymes can also be divided into different subgroups on the basis of the aminoacid residue in the forty-ninth position. Asp49 plays an important role in catalysis and it is conserved in most snake venom $\mathrm{PLA}_{2}$ enzymes, and hence these are identified as D49 enzymes [9]. However, in some of the group IIA PLA 2 enzymes this aminoacid residue is replaced by lysine, serine, asparagine, or arginine and they are identified as K49 [10], S49 [11], N49 [12], or R49 [13] enzymes, respectively. Substitution of Asp in the forty-ninth position interrupts the binding of cofactor $\mathrm{Ca}^{2+}$ to the $\mathrm{Ca}^{2+}$-binding loop, and hence "mutants" show low or no hydrolytic activity $[10,14,15]$. In addition, there are several substitutions in the $\mathrm{Ca}^{2+}$-binding loops of these mutant enzymes.

Secreted phospholipases $\mathrm{A}_{2}$ constitute major components of snake venoms and have been extensively investigated not only because they are very abundant in these venoms but mainly because they display a variety of relevant toxic actions such as neurotoxicity, myotoxicity, cytotoxicity, cardiotoxicity, edema-inducing, artificial membrane disrupting convulsant, hypotensive and proinflammatory effects [7, 16-19]. Besides, they exert a wide range of biological effects, including anticoagulant, platelet aggregation inhibiting $[7,20$, 21], bactericidal [22], anti-HIV [23], antimalarial and antiparasitic [24], antitumor $[21,25,26]$, and recently antiangiogenic effect [27-29]. Due to this functional diversity, these structurally similar proteins aroused the interest of many researchers as molecular models for study of structurefunction relationships. One of the main experimental strategies used for the study of myotoxic $\mathrm{PLA}_{2} \mathrm{~s}$ is the traditional chemical modification of specific aminoacid residues and examination of the consequent effects upon the enzymatic, toxic, and pharmacological activities. Furthermore, some venom $\mathrm{SPLA}_{2}$ have no catalytic activity while they exert various toxic and pharmacological effects $[17,21,26]$. The absence of direct correlation between catalytic activity and pharmacological effects has led to the hypothesis that specific actions of $\mathrm{SPLA}_{2}$ are due to the presence of pharmacological sites on the $\mathrm{PLA}_{2}$ surface overlapping or distinct from the catalytic site. These pharmacological sites would allow the sPLA 2 to bind specifically to soluble or membrane-bound proteins that participate to the $\mathrm{SLA}_{2}$ mechanism of action [30].

Since this hypothesis was proposed, a collection of binding proteins have been identified using several toxic snake venom sPLA 2 [31]. Besides $\beta$-bungarotoxin [32, 33], early studies with the neurotoxic sPLA 2 OS2 from Australian Taipan snake Oxyuranus scutellatus scutellatus have led to the identification of two families of binding proteins called $\mathrm{N}$ and M-type receptors $[31,34,35]$. The $\mathrm{N}$-type receptors are present in mammalian brain and other tissues. Neurotoxic sPLA ${ }_{2}$, such as OS2, bind with $\mathrm{N}$-type receptors with high affinity, while nontoxic sPLA 2 including OS1 bind with much lower affinity, suggesting that these receptors are involved in neurotoxicity.

Conversely, the M-type receptors bind with high affinity both toxic and nontoxic sPLA 2 including OS1 and OS2 [31].
Importantly, the M-type receptors also bind with several mammalian $\mathrm{sPLA}_{2}[31,36]$, suggesting that these proteins are the endogenous ligands for these receptors, and possibly for the collection of binding proteins initially identified with venom $\mathrm{SPLA}_{2}$.

\section{Tunisian Viperidae Snake Venom Proteins}

Snake venom is a natural source for molecules known as modulators of integrin-mediated functions [37]. Pharmacological study of snake venoms reveals structural and functional polymorphisms of proteins they contain. In our laboratory in Pasteur Institute of Tunis, we are interested in studying different pharmacological effects of Tunisian Viperidae venoms, mainly, the horned viper, Cerastes cerastes, Macrovipera lebetina transmediterranea, and Cerastes vipera [38]. Bazaa et al. showed that these venoms contain proteins belonging to a few protein families. However, each venom showed distinct degree of protein composition complexity. The three venoms shared a number of protein classes though the relative occurrence of these toxins was different in each snake species. On the other hand, the venoms of the Cerastes species and Macrovipera lebetina each contained unique components [38]. The comparative proteomic analysis of Tunisian snake venoms provides a comprehensible catalogue of secreted proteins, which may contribute to a deeper understanding of the biological effects of the venoms and may also serve as a starting point for studying structure-function correlations of individual toxins.

Thereby, disintegrins and C-type lectins (CLPs) are among the most studied proteins proved to be components of medical and biotechnological value [39-42]. Indeed, they are potent and specific antagonists of several integrins, such as $\alpha \mathrm{v} \beta 3$ and $\alpha 5 \beta 1[43,44]$ and can thus act in many biological processes including platelet aggregation, angiogenesis, tumor invasion, and bone destruction [39, 45-47]. On the other hand, CLPs were first described as modulators of platelet before their antiadhesive activity was highlighted [48-50]. CLPs are thus able to inhibit integrin-dependent proliferation, migration, invasion, and angiogenesis [26, 44, 51, 52]. Sarray and coworkers have isolated lebectin and lebecetin, two C-type lectins, from Macrovipera lebetina snake venom inhibiting $\alpha 5 \beta 1$ - and $\alpha \mathrm{v}$-containing integrins $[43,44]$. Since their initial characterization, snake venom disintegrins have been extensively studied $[39,46]$, they are potent inhibitors of integrin-ligand interactions. The integrin inhibitory profile of disintegrins primarily depends on the sequence of a tripeptide located at the apex of a mobile loop and constrained in its active conformation by the appropriate pairing of disulfide bonds. So, CC5 and CC8 have been previously characterized as Cerastes cerastes dimeric disintegrins targeting $\alpha_{\mathrm{IIb}} \beta_{3}, \alpha \mathrm{v} \beta 3$, and $\alpha 5 \beta 1$ integrins [53]. In addition to dimeric disintegrins, Macrovipera lebetina venom includes short disintegrin, namely, lebestatin which targets $\alpha 1 \beta 1$ integrin [46].

Recently, phospholipases $\mathrm{A}_{2}\left(\mathrm{PLA}_{2} \mathrm{~s}, \mathrm{EC}\right.$ 3.1.1.4) have been demonstrated to modulate integrins which are essential 


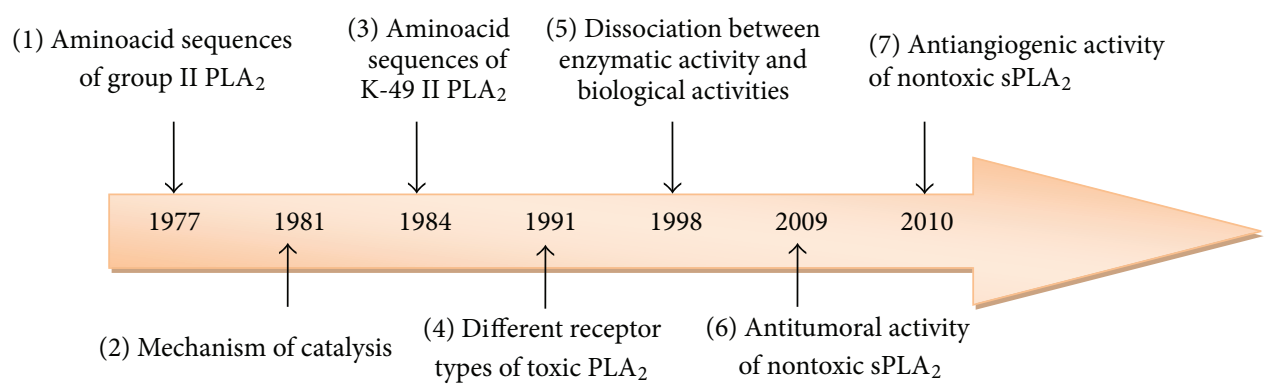

Figure 1: Milestones in PLA, enzyme research. (1) Heinrikson et al. [81], (2) Lambeau et al. [56], (3) Maraganore et al. [10], (4) Lambeau et al. [82], (5) Landucci et al. [83], (6) Zouari-Kessenti et al. [21], Bazaa et al. [27], and (7) [27, 28].

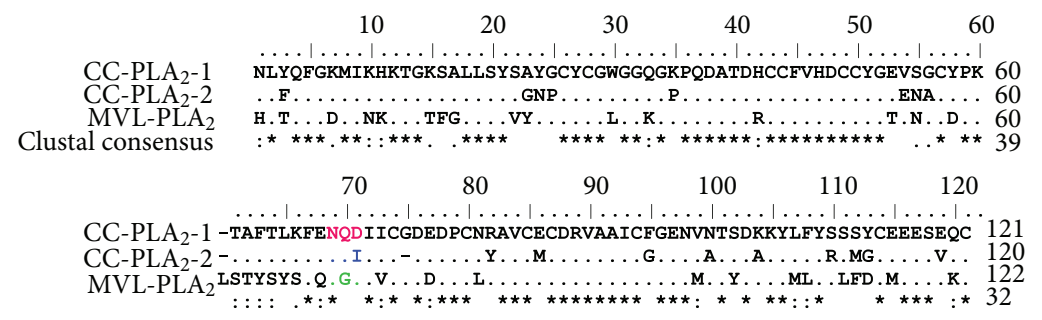

Figure 2: Sequence alignment of Tunisian Viperidae $\mathrm{sLA}_{2}$ : CC-PLA 2 -1 (ACO92622) [28], CC-PLA 2 -2 (ACO92623) [28], and MVL-PLA 2 (CAR40186) [26]. Gaps (-) have been introduced to optimize alignment.

protagonists of the complex multistep process of angiogenesis, the major target for the development of anticancer therapies [21, 27, 28] (Figure 1).

\section{Secreted Phospholipases $A_{2}$ from Tunisian Vipers}

Three acidic, nontoxic, Asp49 phospholipases A2 have been isolated from Tunisian vipers: CC-PLA $2-1$ and CC-PLA $2_{2}^{-}$ 2 from Cerastes cerastes, and MVL-PLA 2 from Macrovipera vipera. They have a molecular weight of 13737.52, 13705.63, and $13626.64 \mathrm{Da}$, respectively. They contain, respectively, 121,120 , and 122 aminoacids, including 14 cysteines each $[21,26]$. The sequences alignment shows similarity as high as $50 \%$ (Figure 2). Furthermore, none of the three PLA2s is cytotoxic up to $2 \mu \mathrm{M}$.

CC-PLA ${ }_{2}-1$ and CC-PLA $2-2$ present a high enzymatic activity [21], while MVL-PLA 2 shows a low one. Although they differ greatly in their catalytic properties, these shared many pharmacological activities proving the lack of correlation between enzymatic and pharmacological activities.

\section{Pharmacological Activities of sPLA 2 from Tunisian Vipers}

CCPLA $_{2}-1$, CC-PLA 2 -2, and MVL-PLA 2 show many pharmacological effects $[21,26]$. The most interesting are the antitumor and antiangiogenic activities which involve integrins $[27,28]$.
5.1. Tunisian Viperidae sPLA $A_{2}$ Effects on Haemostatic System. Snake venom toxins are now regularly used in laboratories for assaying haemostatic parameters and as coagulation reagents $[54,55]$. PLA 2 enzymes are known to inhibit blood coagulation. Depending on the dose required to inhibit coagulation, they are classified into strong, weak, and nonanticoagulant enzymes $[56,57]$. Strong anticoagulant $\mathrm{PLA}_{2}$ enzymes inhibit the activation of FX to FXa by both enzymatic and nonenzymatic mechanisms and inhibit the activation of prothrombin to thrombin by nonenzymatic mechanism $[58,59]$. In our case, $0.14 \mu \mathrm{M}$ of both CC-PLA ${ }_{2}$ s completely inhibited plasma coagulation. Thus, CC-PLA $\mathrm{S}_{2}$ could be considered among the most anticoagulant yet described for $\mathrm{PLA}_{2} \mathrm{~S}$ snake venom [21]. Lizaro and coworkers showed that myotoxin II, a basic PLA $_{2}$ from Bothrops nummifer, was unable to inhibit coagulation of the platelet-poor plasma until $3.57 \mu \mathrm{M}$ [60]. Moreover, it has been shown that BaspPLA(2)-II, an acidic, Asp49 PLA $_{2}$ from Bothrops asper venom lacks anticoagulant activity [61].

Platelet aggregation plays a role in clot retraction and wound healing. Any alteration in platelet aggregation could lead to debilitation or death. CC-PLA 2 -1 and CC-PLA $2_{2}^{-}$ 2 showed high antiplatelet aggregation activities induced by arachidonic acid or ADP [21], contrary to b/D-PLA2 which displays high enzymatic and anticoagulant activities but has no platelet aggregation [62]. Moreover, Kashima and coworkers reported that BthA-I-PLA 2 , a nontoxic acidic $\mathrm{PLA}_{2}$ from Bothrops jararacussu snake venom, inhibited ADP-induced platelet aggregation with moderate effect [63]. 
While, OHVA-PLA 2 , an acidic $\mathrm{PLA}_{2}$ from Ophiophagus hannah, strongly inhibited platelet aggregation in the presence of ADP or arachidonic acid [64]. It thus appears that PLA2 platelet activity is not directly due to its acidic nature or its anticoagulation activity.

\subsection{Tunisian Viperidae sPLA $A_{2}$ Effects on Tumor Cell Behavior.} Snake venom $\mathrm{SPLA}_{2}$ present a wide range of pharmacological effects [7], including cytotoxicity on tumor cells [7, 63, 65]. Concerning CC-PLA $-1, \mathrm{CC}_{2} \mathrm{PLA}_{2}-2$, and MVL$\mathrm{PLA}_{2}$, concentrations up to $2 \mu \mathrm{M}$ during 4 days did not induce detectable cytotoxicity on human cell lines IGR39 (melanoma) and HT1080 (fibrosarcoma) [21, 26].

Adhesion and cell migration are two fundamental steps in numerous diseases, like cancer. CC-PLA $2-1$, CC-PLA $2-2$, and MVL-PLA 2 inhibit adhesion and migration of human HT1080 and IGR39 cells to fibrinogen and fibronectin. This effect persists even after complete blockage of the catalytic activity suggesting that, contrary to Bth-A-I-PLA 2 whose antitumoral effect appears to be linked to enzymatic site [63], the inhibitory and enzymatic activities are supported by different sites. RVV-7, a cytotoxic basic PLA 2 from Russsell's viper venom, inhibits also tumor development [65]. On the contrary, b/D-PLA 2 represents the exception of these enzymes as it stimulates tumor growth [62]. Since Tunisian phospholipases $\mathrm{A}_{2}$ are not cytotoxic, it seems that their antitumoral activity is exerted by a different mechanism. Using different assays, such as a solid-phase binding assay and a panel of immobilized antibodies, we have proved that CC$\mathrm{PLA}_{2}-1, \mathrm{CC}-\mathrm{PLA}_{2}-2$, and MVL-PLA 2 inhibit cell adhesion and migration by interacting directly with $\alpha \mathrm{v}$ and $\alpha 5 \beta 1$ integrins $[26,28]$.

\subsection{Tunisian Viperidae $P L A_{2}$ Effects on Angiogenesis. Angio-} genesis is fundamental to normal healing, reproduction, and embryonic development. However, this process is also important in the pathogenesis of a broad range of disorders such as arthritis and cancer [66]. Angiogenesis is thus required to sustain malignant cells with nutrients and oxygen for tumors to grow beyond a microscopic size. Thus, the microvascular endothelial cell recruited by a tumor is an important target in cancer therapy and has the advantage of being genetically stable. Therefore, treating both the cancer cell and the endothelial cell in a tumor may be more effective than treating the cancer cell alone.

The role of $\alpha \mathrm{v} \beta 3$ integrin in the angiogenic process is well documented [67]. In the last decade, several clinical trials evaluating the efficacy of $\alpha \mathrm{v} \beta 3$ blockers have led to encouraging results in cancer therapy and diagnosis. Similarly, $\alpha 5 \beta 1$ integrin is involved in angiogenesis and more precisely in growing vessels, but its expression disappears in mature vessels [68]. Thereby, when tested in vitro, the two CC-PLA $A_{2}$ and MVL-PLA 2 impaired adhesion and migration of HBMEC (human brain microvascular endothelial cells) and HMEC-1 (human microvascular endothelial cell), respectively, by interfering with integrin function. Moreover, using the CAM assay, an ex vivo model, these $\mathrm{PLA}_{2}$ strongly reduced vasculature development. The treatment reduced the number of new capillaries and branching, without affecting the mature blood vessels, suggesting once again the implication of $\alpha 5 \beta 1$ integrin. Interestingly, CC-PLA $2-1$ and CC$\mathrm{PLA}_{2}-2$ inhibit spontaneous angiogenesis as well as angiogenesis induced by growth factors such as VEGF or bFGF [28]. The antiangiogenic effect of $\mathrm{PLA}_{2}$ can be due partly to the blockage of the $\alpha \mathrm{v} \beta 3$ and $\alpha 5 \beta 1$ integrins functions. However, inhibition of angiogenesis can also result from blockage of VEGF or its receptor. Thus, it has been reported that inactive $\mathrm{PLA}_{2}$ homologues, such as KDR-bp isolated from Eastern cottonmouth venom, are common antagonists of KDR, a VEGF receptor [69].

Focal adhesions are specialized sites of attachment of cells where integrins receptors, such as $\alpha \mathrm{v} \beta 3$, link the extracellular matrix to the actin cytoskeleton, allowing migration [70]. Cell migration is a complex cellular behavior that results from the coordinated changes in the actin cytoskeleton and the controlled formation and dispersal of cell-substrate adhesion sites. While the actin cytoskeleton provides the driving force at the cell front, the microtubule network assumes a regulatory function in coordinating rear retraction. The polarity within migrating cells is further highlighted by the stationary behavior of focal adhesions in the front and their sliding in trailing ends [71].

Treatment of HMEC-1 cells with MVL-PLA 2 induced important changes in cell morphology. Treated cells have a circular shape and actin stress fibers are thinner or absent, with the actin mainly located at the cell periphery. Moreover, MVL-PLA 2 leads to drastic reduction in the size of focal adhesions and their distribution all over the ventral surface of cells, consistent with a decrease in $\alpha \mathrm{v} \beta 3$ integrin clustering and its absence from lamellipodia [27]. Therefore, it appears that the inhibition of migration is associated with important reorganization of the actin cytoskeleton and focal adhesions. Again, there is a clear dissociation between the anti-angiogenic effect and the catalytic activity.

Furthermore, MVL-PLA 2 strongly increased MT dynamicity in HMEC-1 cells. Because the microtubule cytoskeleton is essential in the orchestration of endothelial cell motility $[72,73]$, microtubule-targeting agents are known to have antiangiogenic effects through the modulation of cytoskeleton dynamicity [27]. Thus, microtubule-binding drugs are widely used in cancer chemotherapy and also have clinically relevant antiangiogenic and vascular-disrupting properties [74].

\section{Importance of the Identification of Pharmacological Sites}

The pharmacological sites of $\mathrm{PLA}_{2}$ enzymes determine the affinity between the PLA 2 and target proteins. The identification of pharmacological sites helps in (1) understanding the structure-function relationships of $\mathrm{PLA}_{2}$ enzymes, (2) developing strategies to neutralize the toxicity and pharmacological effects by targeting these sites, and (3) developing prototypes of novel research tools and pharmaceutical drugs $[7,8]$. 


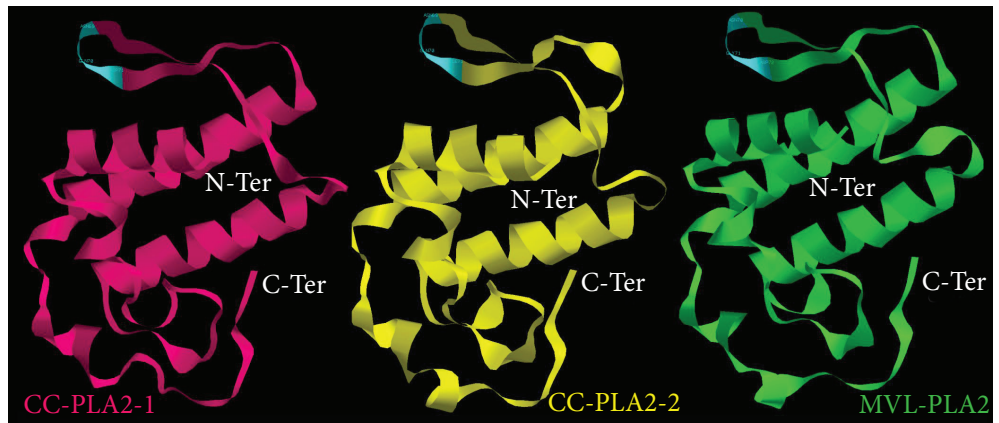

(a)

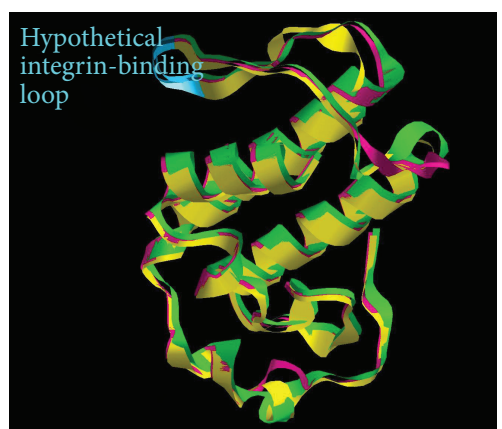

(b)

Figure 3: (a) Tertiary model structure of CC-PLA -1 (pink), CC-PLA 2 -2 (yellow), and MVL-PLA 2 (green). (b) Superimposition of the

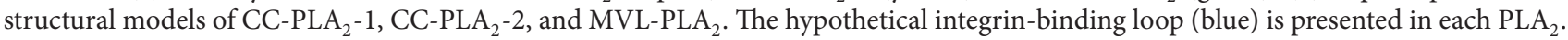

In our studies, we showed that CC-PLA -1, CC-PLA $2^{-}$ 2 , and MVL-PLA ${ }_{2}$ target the $\alpha 5 \beta 1$ and $\alpha \mathrm{v}$ integrins, particularly $\alpha \mathrm{v} \beta 3$. Moreover, angiogenesis involves expression of the later, which binds to RGD-containing components of the interstitial matrix [75].

To further understand the mechanism of action, we report that endothelial cells are able to adhere on immobilized MVL-PLA $A_{2}$ and that this adhesion is impaired by RGD peptides [27]. This suggests that interaction between MVL$\mathrm{PLA}_{2}, \mathrm{CC}-\mathrm{PLA}_{2}-1$, or CC-PLA $2-2$ and integrins involves RGD-like sequence which may be responsible for the inhibition of integrin function. This hypothesis is supported by Ramos and coworkers' study, showing that general folding of electrostatic potential is the main intervening of disintegrinintegrin interaction [76].

When MVL-PLA 2 contains a NGD sequence, which could be considered as an RGD-like motif, CC-PLA -1 and CC-PLA $A_{2}-2$ present NQD and NQI, respectively, that may also be responsible for the inhibition of integrin function.

Therefore, bioinformatics study and structural criteria that would allow identifying biologically active RGD-sites on the base of a protein's spatial structure may become a helpful tool for analysis of cellular function of proteins [77]. Furthermore, conformation of the integrin-binding loop in a protein is defined not only by physicochemical properties and conformation of the sequence itself, but also by its structural environment and therefore of the potential biological activity. Besides the RGD-like sequence site should be placed on a loop or a beta-turn to be well exposed. We can cite disintegrin, like applied model, in which we can note a loop accessible stabilized by disulfide bridges [78].

\section{Molecular Modeling of CC-PLA -1 , CC-PLA 2 -2, and MVL-PLA 2}

In order to examine the site of the suspected RGD-like sequence, using the SWISS-MODEL Workspace (http:// swissmodel.expasy.org/), we have determined the threedimensional models of CC-PLA $2-1$, CC-PLA 2 -2, and MVL$\mathrm{PLA}_{2}$.
Firstly, as shown in Figure 3(a), the three models are very similar. Interestingly, we can note the presence of very-wellexposed loop containing the suspected RGD-like motif. This loop is very similar to that of the disintegrins.

In the case of MVL-PLA 2 , we find the NGD motif, while for CC-PLA -1 and CC-PLA -2 there is NQD and NQI, respectively. According to our hypothesis, the residue $\mathrm{R}$ in RGD motif is replaced by the $\mathrm{N}$ which is hydrophilic and polar residue, it is even more hydrophilic than $\mathrm{R}$ residue, this leads to higher affinity towards the $\alpha \mathrm{v} \beta 3$ integrin [79]. Besides, the D residue favors recognition of $\alpha \mathrm{v} \beta 3$ and $\alpha 5 \beta 1$ integrins [79]. In addition, in CC-PLA ${ }_{2}-1$ and CC-PLA ${ }_{2}^{-}$ 2 the RGD-like motif is flanked by two E residues, highly polarized which could enhance the inhibitory effect towards integrins that bind to ligands through RGD sites, including the fibronectin receptor, mainly, the $\alpha 5 \beta 1$ integrin [80].

On the other side, based on the study of disintegrins, it is known that integrin-binding ability is apparently more related to the Cys-rich domain. Similarly, CC-PLA $2-1$, CC$\mathrm{PLA}_{2}-2$, and MVL-PLA 2 present 14 Cys forming 7 disulfides bridges. We can postulate that disulfide bonds, especially Cys50-Cys86 and Cys57-Cys79, stabilized the hypothetical integrin-binding loop. The superimposition of the structural models of CC-PLA $2-1$, CC-PLA $2-2$, and MVL-PLA 2 shows that they share similar conformational features (Figure 3(b)).

Nevertheless, further structure-function relationships study must be carried to verify this hypothesis.

\section{Conclusion}

Secreted phospholipase $\mathrm{A}_{2}$ enzymes, especially from Viperidae Snake venom, exhibit a wide variety of pharmacological effects despite their structure similarity. These enzymes provide a great challenge to protein chemists as subtle and complex puzzles in structure-function relationship. A better understanding will contribute to our knowledge of proteinprotein interactions, protein targeting, and protein engineering, and to the development of better-targeted delivery systems. Further research in identifying target proteins will bring details on the mechanisms of the pharmacological effects at the cellular and molecular levels. Studies in these 
areas will result in new, exciting, and innovative opportunities in the future, both in finding answers to the toxicity of $\mathrm{PLA}_{2}$ enzymes and could bring useful tools for developing proteins with novel functions.

Interestingly, we have demonstrated that two isoforms of $\mathrm{PLA}_{2}$ (CC-PLA -1 and -2), from horned Tunisian viper Cerastes cerastes and another from Macrovipera lebetina MVL-PLA 2 target integrins, a large and very important family of adhesion molecules that promote stable interactions between cells and their environment $[26,28]$. Indeed, these $\mathrm{sPLA}_{2}$ exhibit a potent antitumor and antiangiogenic activities. We showed that their effect is likely due to the inhibition of $\alpha 5 \beta 1$ - and $\alpha \mathrm{V}$-containing integrins [26, 28].

These nontoxic secreted phospholipase $\mathrm{A}_{2}$ could be new tools to disrupt different steps of tumor and angiogenesis progression through integrins. It is noteworthy that this effect is independent of the enzymatic activity. This finding may serve, on the one hand, as a mean to discuss the molecular regions involved in recognition of tissue targets and, on the other hand, as starting point structure-function relationship studies leading to design a new generation of anticancer drugs.

\section{Abbreviations}

sPLA 2 : Secreted phospholipase $\mathrm{A}_{2}$

CLP: C-type lectin protein

VEGF: Vascular endothelial growth factor

bFGF: Basic fibroblast growth factor

CAM: Chick chorioallantoic membrane.

\section{References}

[1] R. Doley and R. M. Kini, "Protein complexes in snake venom," Cellular and Molecular Life Sciences, vol. 66, no. 17, pp. 2851-2871, 2009.

[2] D. C. I. Koh, A. Armugam, and K. Jeyaseelan, "Snake venom components and their applications in biomedicine," Cellular and Molecular Life Sciences, vol. 63, no. 24, pp. 3030-3041, 2006.

[3] M. F. El-Refaei and N. H. Sarkar, "Snake venom inhibits the growth of mouse mammary tumor cells in vitro and in vivo," Toxicon, vol. 54, pp. 33-41, 2009.

[4] V. Guimarães-Gomes, A. L. Oliveira-Carvalho, I. D. L. M. Junqueira-De-Azevedo et al., "Cloning, characterization, and structural analysis of a C-type lectin from Bothrops insularis (BiL) venom," Archives of Biochemistry and Biophysics, vol. 432, no. 1, pp. 1-11, 2004.

[5] K. Stocker, "Use of snake venom proteins in medicine," Schweizerische Medizinische Wochenschrift, vol. 129, no. 6, pp. 205-216, 1999.

[6] R. C. De Paula, H. C. Castro, C. R. Rodrigues, P. A. Melo, and A. L. Fuly, "Structural and pharmacological features of phospholipases $\mathrm{A}_{2}$ from snake venoms," Protein and Peptide Letters, vol. 16, no. 8, pp. 899-907, 2009.

[7] R. Lakshminarayanan, S. Valiyaveettil, V. S. Rao, and R. M. Kini, "Purification, characterization, and in vitro mineralization studies of a novel goose eggshell matrix protein, ansocalcin," Journal of Biological Chemistry, vol. 278, no. 5, pp. 2928-2936, 2003.
[8] R. Doley, X. Zhou, and R. M. Kini, Venoms and Toxins of Reptiles, edited by S. P. Mackessy, University of Northern Colorado, Greeley, Colo, USA, 2010.

[9] P. H. C. Ciscotto, B. Rates, D. A. F. Silva et al., "Venomic analysis and evaluation of antivenom cross-reactivity of South American Micrurus species," Journal of Proteomics, vol. 74, pp. 1810-1825, 2011.

[10] J. M. Maraganore, G. Merutka, and W. Cho, "A new class of phospholipases $\mathrm{A}_{2}$ with lysine in place of aspartate 49. Functional consequences for calcium and substrate binding," Journal of Biological Chemistry, vol. 259, no. 22, pp. 13839-13843, 1984.

[11] J. Polgár, E. M. Magnenat, M. C. Peitsch, T. N. C. Wells, and K. J. Clemetson, "Asp-49 is not an absolute prerequisite for the enzymic activity of low-Mr phospholipases $\mathrm{A}_{2}$ : purification, characterization and computer modelling of an enzymically active Ser- 49 phospholipase $A_{2}$, ecarpholin S, from the venom of Echis carinatus sochureki (saw-scaled viper)," Biochemical Journal, vol. 319, no. 3, pp. 961-968, 1996.

[12] I. H. Tsai, Y. M. Wang, Y. H. Chen, T. S. Tsai, and M. C. $\mathrm{Tu}$, "Venom phospholipases $\mathrm{A}_{2}$ of bamboo viper (Trimeresurus stejnegeri): molecular characterization, geographic variations and evidence of multiple ancestries," Biochemical Journal, vol. 377, no. 1, pp. 215-223, 2004.

[13] T. Chijiwa, E. Tokunaga, R. Ikeda et al., "Discovery of novel [Arg49]phospholipase $\mathrm{A}_{2}$ isozymes from Protobothrops elegans venom and regional evolution of Crotalinae snake venom phospholipase $\mathrm{A}_{2}$ isozymes in the southwestern islands of Japan and Taiwan," Toxicon, vol. 48, no. 6, pp. 672-682, 2006.

[14] J. M. Maraganore and R. L. Heinrikson, "The role of lysyl residues of phospholipase $A_{2}$ in the formation of the catalytic complex," Biochemical and Biophysical Research Communications, vol. 131, no. 1, pp. 129-138, 1985.

[15] J. I. Dos Santos, M. Cintra-Francischinelli, R. J. Borges et al., "Structural, functional, and bioinformatics studies reveal a new snake venom homologue phospholipase $\mathrm{A}_{2}$ class," Proteins, vol. 79, no. 1, pp. 61-78, 2011.

[16] K. Shimuta, M. Ohnishi, S. Iyoda, N. Gotoh, N. Koizumi, and H. Watanabe, "The hemolytic and cytolytic activities of Serratia marcescens phospholipase A(PhlA) depend on lysophospholipid production by PhlA," BMC Microbiology, vol. 9, article 261, 2009.

[17] D. P. Marchi-Salvador, C. A. H. Fernandes, L. B. Silveira, A. M. Soares, and M. R. M. Fontes, "Crystal structure of a phospholipase $\mathrm{A}_{2}$ homolog complexed with p-bromophenacyl bromide reveals important structural changes associated with the inhibition of myotoxic activity," Biochimica et Biophysica Acta, vol. 1794, no. 11, pp. 1583-1590, 2009.

[18] M. T. Murakami, M. R. Lourenzoni, E. Z. Arruda et al., "Biochemical and structural investigations of bothropstoxinII, a myotoxic Asp49 phospholipase $\mathrm{A}_{2}$ from Bothrops jararacussu venom," Protein and Peptide Letters, vol. 15, no. 9, pp. 1002-1008, 2008.

[19] C. Barja-Fidalgo, A. L. J. Coelho, R. Saldanha-Gama, E. HelalNeto, A. Mariano-Oliveira, and M. S. de Freitas, "Disintegrins: integrin selective ligands which activate integrin-coupled signaling and modulate leukocyte functions," Brazilian Journal of Medical and Biological Research, vol. 38, no. 10, pp. 1513-1520, 2005.

[20] V. L. Karbovskiy, O. M. Savchuk, G. L. Volkov, N. V. Zaichko, and T. Buchan, "Influence of proteins from the Agkistrodon blomhoffii ussuriensis snake venom on platelets," Ukrain'skyi Biokhimichnyi Zhurnal, vol. 79, no. 4, pp. 82-89, 2007. 
[21] R. Zouari-Kessentini, J. Luis, A. Karray et al., "Two purified and characterized phospholipases $\mathrm{A}_{2}$ from Cerastes cerastes venom, that inhibit cancerous cell adhesion and migration," Toxicon, vol. 53, no. 4, pp. 444-453, 2009.

[22] R. P. Samy, P. Gopalakrishnakone, M. M. Thwin et al., "Antibacterial activity of snake, scorpion and bee venoms: a comparison with purified venom phospholipase $\mathrm{A}_{2}$ enzymes," Journal of Applied Microbiology, vol. 102, no. 3, pp. 650-659, 2007.

[23] D. Fenard, G. Lambeau, E. Valentin, J. C. Lefebvre, M. Lazdunski, and A. Doglio, "Secreted phospholipases $\mathrm{A}_{2}$, a new class of HIV inhibitors that block virus entry into host cells," Journal of Clinical Investigation, vol. 104, no. 5, pp. 611-618, 1999.

[24] C. Deregnaucourt and J. Schrével, "Bee venom phospholipase $\mathrm{A}_{2}$ induces stage-specific growth arrest of the intraerythrocytic Plasmodium falciparum via modifications of human serum components," Journal of Biological Chemistry, vol. 275, no. 51, pp. 39973-39980, 2000.

[25] D. Jerusalinsky, E. Kornisiuk, R. Bernabeu, I. Izquierdo, and C. Cervenanskyl, "Muscarinic toxins from the venom of Dendroaspis snakes with agonist-like actions," Toxicon, vol. 33, no. 4, pp. 389-397, 1995.

[26] J. Jebali, A. Bazaa, S. Sarray et al., "C-type lectin protein isoforms of Macrovipera lebetina: cDNA cloning and genetic diversity," Toxicon, vol. 53, no. 2, pp. 228-237, 2009.

[27] A. Bazaa, E. Pasquier, C. Defilles et al., "MVL-PLA 2 , a snake venom phospholipase $A_{2}$, inhibits angiogenesis through an increase in microtubule dynamics and disorganization of focal adhesions," PLoS ONE, vol. 5, no. 4, Article ID e10124, 2010.

[28] R. Kessentini-Zouari, J. Jebali, S. Taboubi et al., "CC-PLA ${ }_{2}^{-}$ 1 and CC-PLA ${ }_{2}-2$, two Cerastes cerastes venom-derived phospholipases $\mathrm{A}_{2}$, inhibit angiogenesis both in vitro and in vivo," Laboratory Investigation, vol. 90, no. 4, pp. 510-519, 2010.

[29] D. Fujisawa, Y. Yamazaki, B. Lomonte, and T. Morita, "Catalytically inactive phospholipase $\mathrm{A}_{2}$ homologue binds to vascular endothelial growth factor receptor-2 via a C-terminal loop region," Biochemical Journal, vol. 411, no. 3, pp. 515-522, 2008.

[30] R. Majunatha Kini and H. J. Evans, "A model to explain the pharmacological effects of snake venom phospholipases $A_{2}$," Toxicon, vol. 27, no. 6, pp. 613-635, 1989.

[31] L. Cupillard, R. Mulherkar, N. Gomez et al., "Both group IB and group IIA secreted phospholipases $\mathrm{A}_{2}$ are natural ligands of the mouse $180-\mathrm{kDa}$ M-type receptor," Journal of Biological Chemistry, vol. 274, no. 11, pp. 7043-7051, 1999.

[32] H. Rehm, T. Schafer, and H. Betz, “ $\beta$-Bungarotoxin-induced cell-death of neurons in chick retina," Brain Research, vol. 250, no. 2, pp. 309-319, 1982.

[33] H. Rehm, "Molecular aspects of neuronal voltage-dependent K+ channels," European Journal of Biochemistry, vol. 202, no. 3, pp. 701-713, 1991.

[34] G. Lambeau, P. Ancian, J. P. Nicolas, L. Cupillard, E. Zvaritch, and M. Lazdunski, "A family of receptors for secretory phospholipases $\mathrm{A}_{2}$," Comptes Rendus des Séances de la Société de Biologie et de ses Filiales, vol. 190, no. 4, pp. 425-435, 1996.

[35] G. Lambeau, J. Barhanin, H. Schweitz, J. Qar, and M. Lazdunski, "Identification and properties of very high affinity brain membrane-binding sites for a neurotoxic phospholipase from the taipan venom," Journal of Biological Chemistry, vol. 264, no. 19, pp. 11503-11510, 1989.

[36] K. Hanasaki and H. Arita, "Phospholipase $A_{2}$ receptor: a regulator of biological functions of secretory phospholipase $\mathrm{A}_{2}$," Prostaglandins and Other Lipid Mediators, vol. 68-69, pp. 71-82, 2002.
[37] T. F. Huang, "What have snakes taught us about integrins?" Cellular and Molecular Life Sciences, vol. 54, no. 6, pp. 527-540, 1998.

[38] A. Bazaa, N. Marrakchi, M. El Ayeb, L. Sanz, and J. J. Calvete, "Snake venomics: comparative analysis of the venom proteomes of the Tunisian snakes Cerastes cerastes, Cerastes vipera and Macrovipera lebetina," Proteomics, vol. 5, no. 16, pp. 4223-4235, 2005.

[39] M. A. McLane, T. Joerger, and A. Mahmoud, "Disintegrins in health and disease," Frontiers in Bioscience, vol. 13, pp. 6617-6637, 2008.

[40] K. J. Clemetson, Q. Lu, and J. M. Clemetson, "Snake C-type lectin-like proteins and platelet receptors," Pathophysiology of Haemostasis and Thrombosis, vol. 34, no. 4-5, pp. 150-155, 2006.

[41] L. C. Wijeyewickrema, M. C. Berndt, and R. K. Andrews, "Snake venom probes of platelet adhesion receptors and their ligands," Toxicon, vol. 45, no. 8, pp. 1051-1061, 2005.

[42] X. Lu, D. Lu, M. F. Scully, and V. V. Kakkar, "Integrins in drug targeting-RGD templates in toxins," Current Pharmaceutical Design, vol. 12, no. 22, pp. 2749-2769, 2006.

[43] S. Sarray, E. Delamarre, J. Marvaldi, M. E. Ayeb, N. Marrakchi, and J. Luis, "Lebectin and lebecetin, two C-type lectins from snake venom, inhibit $\alpha 5 \beta 1$ and $\alpha \mathrm{v}$-containing integrins," Matrix Biology, vol. 26, no. 4, pp. 306-313, 2007.

[44] S. Sarray, J. Luis, M. El Ayeb, and N. Marrakchi, "Snake venoms C-type lectins and their receptors on platelets and cancerous cells," Archives de l'Institut Pasteur de Tunis, vol. 85, no. 1-4, pp. 69-80, 2008.

[45] R. K. Andrews and M. C. Berndt, "Snake venom modulators of platelet adhesion receptors and their ligands," Toxicon, vol. 38, no. 6, pp. 775-791, 2000.

[46] K. Z. Olfa, L. José, D. Salma et al., "Lebestatin, a disintegrin from Macrovipera venom, inhibits integrin-mediated cell adhesion, migration and angiogenesis," Laboratory Investigation, vol. 85, no. 12, pp. 1507-1516, 2005.

[47] R. J. Carbajo, L. Sanz, S. Mosulén et al., "NMR structure and dynamics of recombinant wild type and mutated jerdostatin, a selective inhibitor of integrin $\alpha 1 \beta 1$," Proteins, vol. 79, no. 8 , pp. 2530-2542, 2011.

[48] B. B. Vargaftig, J. Prado-Franceschi, and M. Chignard, "Activation of guinea-pig platelets induced by convulxin, a substance extracted from the venom of Crotalus durissus cascavella," European Journal of Pharmacology, vol. 68, no. 4, pp. 451-464, 1980.

[49] B. B. Vargaftig, D. Joseph, G. Marlas, and L. G. Chevance, "Degranulation of rabbit platelets with PAF-acether: a new procedure for unravelling the mode of action of plateletactivating substances," Thrombosis and Haemostasis, vol. 48, no. 1, pp. 67-71, 1982.

[50] J. Polgár, J. M. Clemetson, B. E. Kehrel et al., "Platelet activation and signal transduction by convulxin, a C-type lectin from Crotalus durissus terrificus (Tropical rattlesnake) venom via the p62/GPVI collagen receptor," Journal of Biological Chemistry, vol. 272, no. 21, pp. 13576-13583, 1997.

[51] S. Sarray, N. Srairi, J. Luis, J. Marvaldi, M. El Ayeb, and N. Marrakchi, "Lebecetin, a C-lectin protein from the venom of Macrovipera lebetina that inhibits platelet aggregation and adhesion of cancerous cells," Haemostasis, vol. 31, no. 3-6, pp. 173-176, 2001. 
[52] A. Pilorget, M. Conesa, S. Sarray et al., "Lebectin, a Macrovipera lebetina venom-derived C-type lectin, inhibits angiogenesis both in vitro and in vivo," Journal of Cellular Physiology, vol. 211, no. 2, pp. 307-315, 2007.

[53] J. J. Calvete, J. W. Fox, A. Agelan, S. Niewiarowski, and C. Marcinkiewicz, "The presence of the WGD motif in CC8 heterodimeric disintegrin increases its inhibitory effect on $\alpha \mathrm{IIb} \beta 3, \alpha \mathrm{v} \beta 3$, and $\alpha 5 \beta 1$ integrins," Biochemistry, vol. 41 , no. 6 , pp. 2014-2021, 2002.

[54] R. M. Kini and H. J. Evans, "Structure-function relationships of phospholipases. The anticoagulant region of phospholipases $\mathrm{A}_{2}$," Journal of Biological Chemistry, vol. 262, no. 30, pp. 14402-14407, 1987.

[55] R. M. Kini, "Anticoagulant proteins from snake venoms: structure, function and mechanism," Biochemical Journal, vol. 397, no. 3, pp. 377-387, 2006.

[56] G. Lambeau, P. Ancian, J. P. Nicolas et al., "Structural elements of secretory phospholipases $\mathrm{A}_{2}$ involved in the binding to $\mathrm{M}$ type receptors," Journal of Biological Chemistry, vol. 270, no. 10, pp. 5534-5540, 1995.

[57] G. A. Boffa, M. C. Boffa, and J. J. Winchenne, "A phospholipase $\mathrm{A}_{2}$ with anticoagulant activity. I. Isolation from Vipera berus venom and properties," Biochimica et Biophysica Acta, vol. 429, no. 3, pp. 828-838, 1976.

[58] R. T. Kerns, R. M. Kini, S. Stefansson, and H. J. Evans, "Targeting of venom phospholipases: the strongly anticoagulant phospholipase $A_{2}$ from Naja nigricollis venom binds to coagulation factor Xa to inhibit the prothrombinase complex," Archives of Biochemistry and Biophysics, vol. 369, no. 1, pp. 107-113, 1999.

[59] R. Manjunatha Kini and H. J. Evans, "The role of enzymatic activity in inhibition of the extrinsic tenase complex by phospholipase $\mathrm{A}_{2}$ isoenzymes from Naja nigricollis venom," Toxicon, vol. 33, no. 12, pp. 1585-1590, 1995.

[60] S. Lizano, Y. Angulo, B. Lomonte et al., "Two phospholipase $\mathrm{A}_{2}$ inhibitors from the plasma of Cerrophidion (Bothrops) godmani which selectively inhibit two different group-II phospholipase $\mathrm{A}_{2}$ myotoxins from its own venom: isolation, molecular cloning and biological properties," Biochemical Journal, vol. 346, no. 3, pp. 631-639, 2000.

[61] J. Fernández, J. M. Gutiérrez, Y. Angulo et al., "Isolation of an acidic phospholipase $A_{2}$ from the venom of the snake Bothrops asper of Costa Rica: biochemical and toxicological characterization," Biochimie, vol. 92, no. 3, pp. 273-283, 2010.

[62] D. A. Higuchi, C. M. V. Barbosa, C. Bincoletto et al., "Purification and partial characterization of two phospholipases $\mathrm{A}_{2}$ from Bothrops leucurus (white-tailed-jararaca) snake venom," Biochimie, vol. 89, no. 3, pp. 319-328, 2007.

[63] S. Kashima, P. G. Roberto, A. M. Soares et al., "Analysis of Bothrops jararacussu venomous gland transcriptome focusing on structural and functional aspects: I-gene expression profile of highly expressed phospholipases $\mathrm{A}_{2}$," Biochimie, vol. 86, no. 3, pp. 211-219, 2004.

[64] M. Z. Huang, P. Gopalakrishnakone, and R. M. Kini, "Role of enzymatic activity in the antiplatelet effects of a phospholipase $\mathrm{A}_{2}$ from Ophiophagus hannah snake venom," Life Sciences, vol. 61, no. 22, pp. 2211-2217, 1997.

[65] G. Maity, S. Mandal, P. Bhattacharjee, and D. Bhattacharyya, "Thermal detoxification of the venom from Daboia russelli russelli of Eastern India with restoration of fibrinolytic activity," Toxicon, vol. 57, no. 5, pp. 747-754, 2011.

[66] J. Folkman, "Angiogenesis: an organizing principle for drug discovery?" Nature Reviews Drug Discovery, vol. 6, no. 4, pp. 273-286, 2007.

[67] P. Ernsberger, M. E. Graves, L. M. Graff et al., "I1-imidazoline receptors-definition, characterization, distribution, and transmembrane signaling," Annals of the New York Academy of Sciences, vol. 763, pp. 22-42, 1995.

[68] J. D. Watson and E. J. Milner-White, "The conformations of polypeptide chains where the main-chain parts of successive residues are enantiomeric. Their occurrence in cation and anion-binding regions of proteins," Journal of Molecular Biology, vol. 315, no. 2, pp. 183-191, 2002.

[69] Y. Yamazaki, Y. Matsunaga, Y. Nakano, and T. Morita, "Identification of vascular endothelial growth factor receptor-binding protein in the venom of eastern cottonmouth: a new role of snake venom myotoxic LYS49-phospholipase $\mathrm{A}_{2}$," Journal of Biological Chemistry, vol. 280, no. 34, pp. 29989-29992, 2005.

[70] M. L. Gardel, B. Sabass, L. Ji, G. Danuser, U. S. Schwarz, and C. M. Waterman, "Traction stress in focal adhesions correlates biphasically with actin retrograde fl ow speed," Journal of Cell Biology, vol. 183, no. 6, pp. 999-1005, 2008.

[71] B. Wehrle-Haller and B. A. Imhof, "Actin, microtubules and focal adhesion dynamics during cell migration," International Journal of Biochemistry and Cell Biology, vol. 35, no. 1, pp. 39-50, 2003.

[72] D. H. Madsen, S. Ingvarsen, H. J. Jürgensen et al., "The nonphagocytic route of collagen uptake: a distinct degradation pathway," Journal of Biological Chemistry, vol. 286, no. 30, pp. 26996-27010, 2011.

[73] K. Zaoui, K. Benseddik, P. Daou, D. Salaün, and A. Badache, "ErbB2 receptor controls microtubule capture by recruiting ACF7 to the plasma membrane of migrating cells," Proceedings of the National Academy of Sciences of the United States of America, vol. 107, no. 43, pp. 18517-18522, 2010.

[74] S. Elifio-Esposito, L. Tomazeli, C. Schwartz et al., "Human neutrophil migration and activation by BJcuL, a galactose binding lectin purified from Bothrops jararacussu venom," BMC Immunology, vol. 12, article 10, 2011.

[75] J. Folkman, "Tumor angiogenesis: therapeutic implications," New England Journal of Medicine, vol. 285, no. 21, pp. 1182-1186, 1971.

[76] F. P. Silva, G. M. C. Alexandre, C. H. I. Ramos, and S. G. DeSimone, "On the quaternary structure of a C-type lectin from Bothrops jararacussu venom-BJ-32 (BjcuL)," Toxicon, vol. 52, no. 8, pp. 944-953, 2008.

[77] I. Y. Torshin, "Structural criteria of biologically active RGDsites for analysis of protein cellular function-a bioinformatics study," Medical Science Monitor, vol. 8, no. 8, pp. BR301-BR312, 2002.

[78] D. H. F. Souza, M. R. C. Iemma, L. L. Ferreira et al., "The disintegrin-like domain of the snake venom metalloprotease alternagin inhibits $\alpha 2 \beta 1$ integrin-mediated cell adhesion," Archives of Biochemistry and Biophysics, vol. 384, no. 2, pp. 341-350, 2000.

[79] U. Hersel, C. Dahmen, and H. Kessler, "RGD modified polymers: biomaterials for stimulated cell adhesion and beyond," Biomaterials, vol. 24, no. 24, pp. 4385-4415, 2003.

[80] J. J. Calvete, M. P. Moreno-Murciano, R. D. G. Theakston, D. G. Kisiel, and C. Marcinkiewicz, "Snake venom disintegrins: 
novel dimeric disintegrins and structural diversification by disulphide bond engineering," Biochemical Journal, vol. 372, no. 3, pp. 725-734, 2003.

[81] R. L. Heinrikson, E. T. Krueger, and P. S. Keim, "Amino acid sequence of phospholipase $\mathrm{A}_{2} \alpha$ from the venom of Crotalus adamanteus. A new classification of phospholipases $\mathrm{A}_{2}$ based upon structural determinants," Journal of Biological Chemistry, vol. 252, no. 14, pp. 4913-4921, 1977.

[82] G. Lambeau, J. Barhanin, and M. Lazdunski, "Identification of different receptor types for toxic phospholipases $\mathrm{A}_{2}$ in rabbit skeletal muscle," FEBS Letters, vol. 293, no. 1-2, pp. 29-33, 1991.

[83] E. C. T. Landucci, R. C. Castro, M. F. Pereira et al., "Mast cell degranulation induced by two phospholipase $\mathrm{A}_{2}$ homologues: dissociation between enzymatic and biological activities," European Journal of Pharmacology, vol. 343, no. 2-3, pp. 257-263, 1998. 

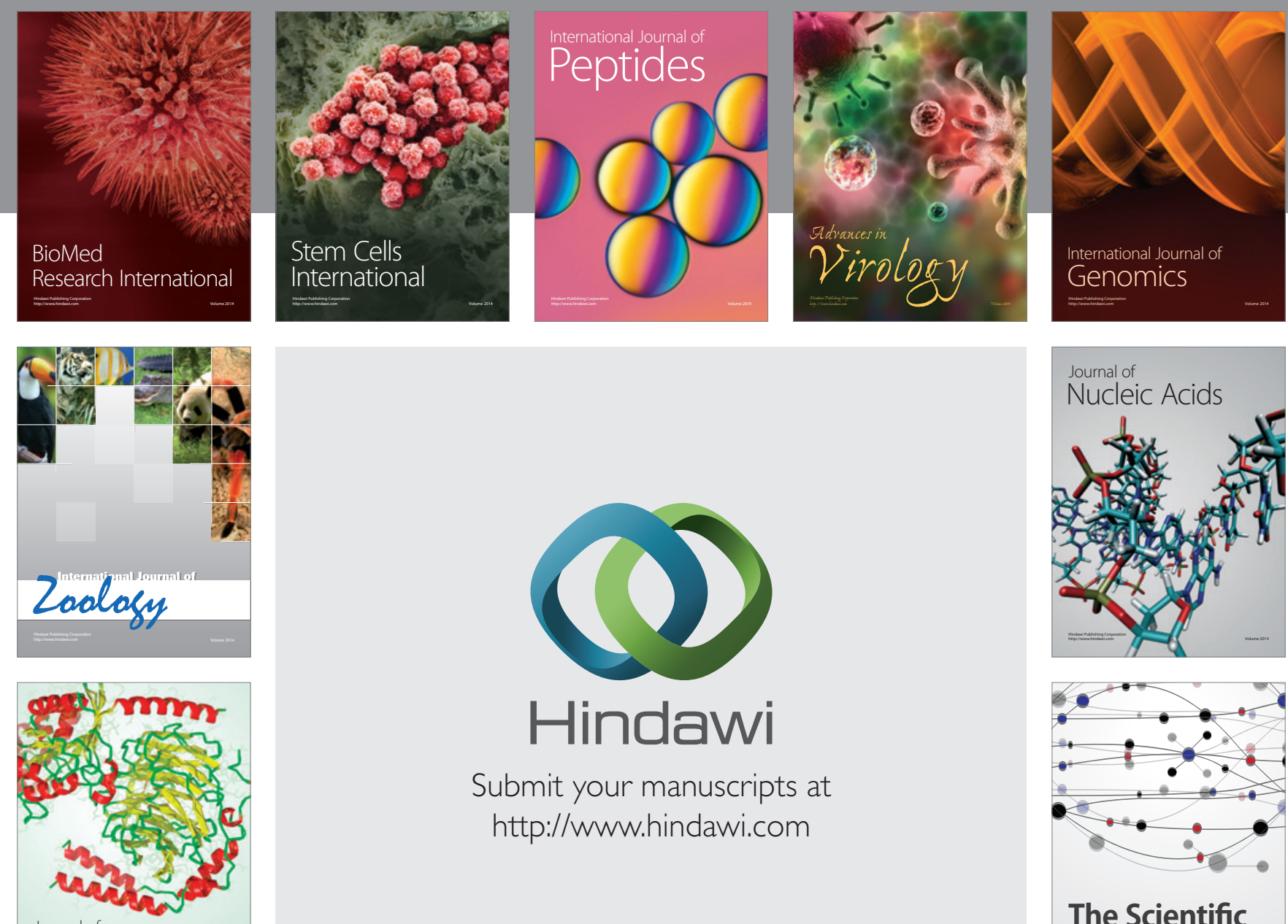

Submit your manuscripts at

http://www.hindawi.com

Journal of
Signal Transduction
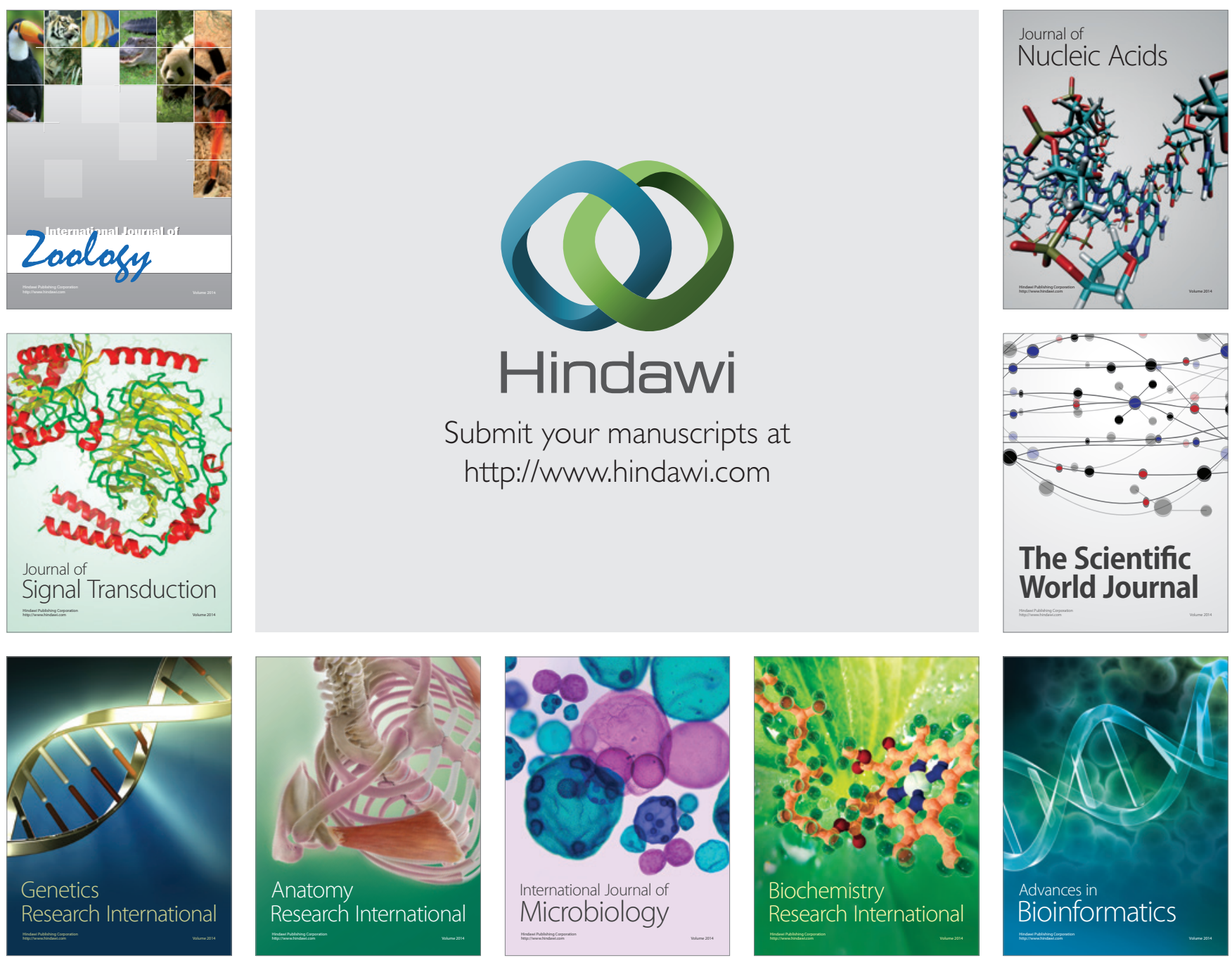

The Scientific World Journal
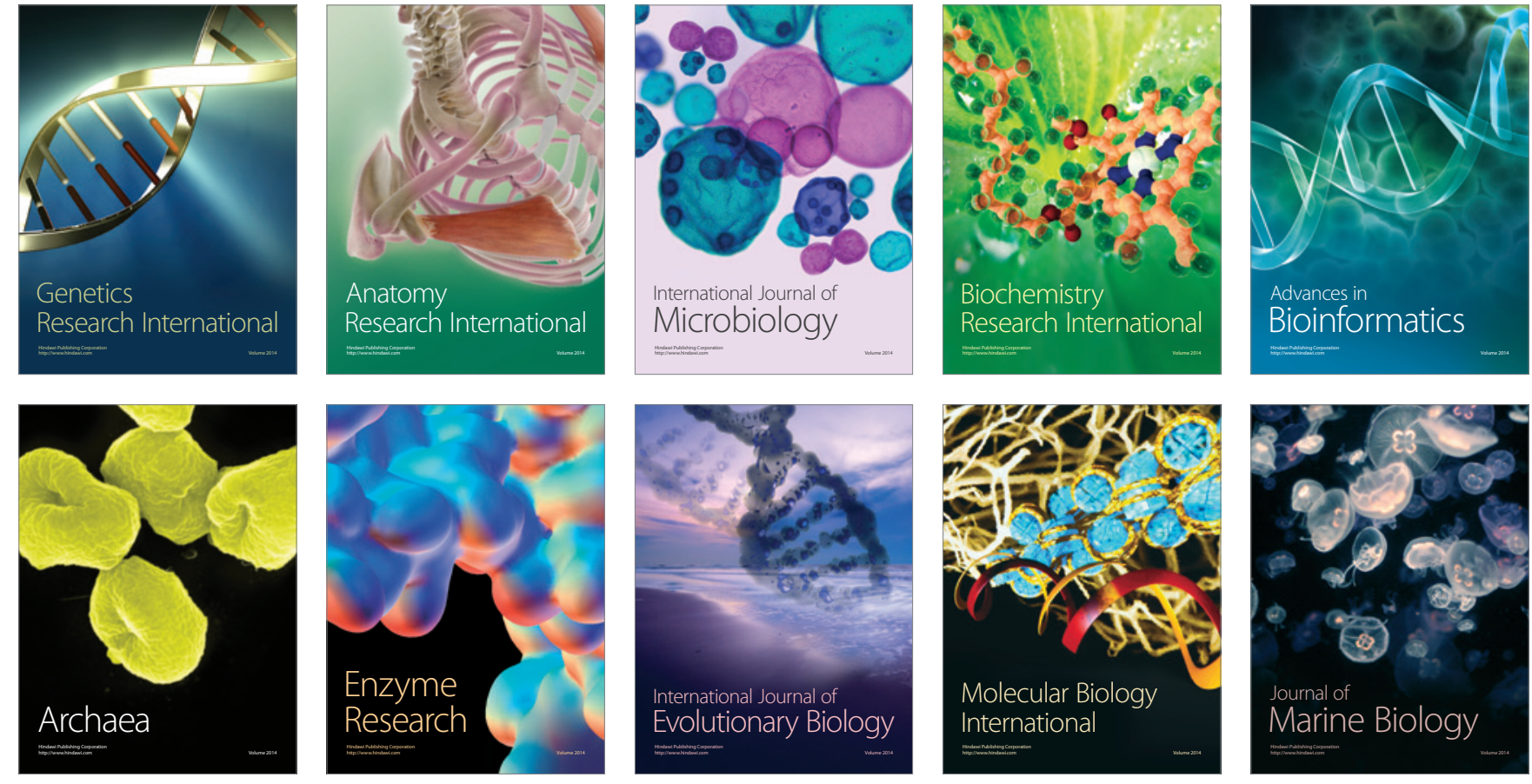